\title{
RELIGION IN HONG KONG EDUCATION: REPRESENTATION IN LIBERAL STUDIES TEXTBOOKS
}

\author{
Liz Jackson
}

Faculty of Education, University of Hong Kong, Hong Kong

Liz Jackson, Assistant Professor, Faculty of Education, University of Hong Kong.

\begin{abstract}
Hong Kong's Liberal Studies curriculum (implemented in 2009) aims in part to teach young people about diversity in society, including cultural, ethnic, and religious diversity. This essay considers how religions and religious diversity are represented in Liberal Studies, analyzing how minority forms of religion are visible and invisible in the four most popular Liberal Studies textbook sets. The analysis will answer the questions of (1) how Hong Kong's religious diversity is expressed in the textbooks and (2) how different religions are depicted in relation to the society overall. Textbooks are the primary source material teachers use, particularly in new subjects, as reflections of prevalent attitudes, beliefs, and norms, and as formal sources of curriculum content. This essay therefore provides a glimpse of the latent knowledge about religious diversity in the educational publishing and decision making community of Hong Kong, relating gaps in text coverage to the subject's aim of developing student understanding and appreciation of diversity
\end{abstract}

Keywords: curriculum, religion, education, Hong Kong, Islam 
One aim of education is to teach young people about diversity in society and around the world. Hong Kong’s new Senior Secondary “Liberal Studies” curriculum (introduced in 2009) contributes toward these ends as the one required subject in secondary education that deals with social studies topics, with such modules as “Hong Kong Today,” "Modern China,” and “Globalization.” Liberal Studies’ goals are philosophical and practical at once. They include “to help students appreciate and respect diversity in cultures and views in a pluralistic society" (CDC 2007, 5). However, to appreciate or respect diversity in practice, one should also develop awareness of the more tangible impacts of cultural diversity in society, understanding particular diverse norms, rather than expressing only broad generalizations of tolerance and recognition.

This essay provides an overview of how religions and religious diversity are represented in the Hong Kong curriculum, analyzing how minority, migrant, and marginalized forms of religion in Hong Kong are visible and absent in the four most frequently used Liberal Studies text sets. The analysis will consider how Hong Kong's religious diversity is expressed in the textbooks, and how different religions are depicted generally. Textbooks are typically the primary classroom resource teachers use, as they are commonly regarded as official sources of curriculum content. However, textbooks can also be seen, especially in social studies subjects (such as history, geography, and Liberal Studies), to reflect prevalent attitudes, beliefs, and norms, as latent, or unintentional knowledge can be seen to emerge when one critically examines what is and is not included in portraying the social world (Jackson 2011; Jackson 2014). 
Textbook production and expression should not be understood as merely neutral and objective (especially in social studies), but rather is framed by ideological and political contexts (Crawford and Foster 2006; de Leon Mendiola 2007; Peng \& Huang 2012). These contexts are not unique to the textbook publication industry, but intertwine with the world of educators choosing, purchasing, and using textbooks, as publishers aim to meet needs developed and identified by educational planners and classroom teachers. Thus, although the subject of Liberal Studies clearly has multicultural aims, a lack of meaningful exploration of diversity within the content of the textbooks can reflect ambivalence in the educational community of Hong Kong about the value of diversity and positive recognition of difference. In relation, ambivalence about multiculturalism has also been identified in policies related to education of ethnic minority children in Hong Kong (see Law and Lee 2012), with public schools asking for more guidance from the Education Bureau for supporting this community (Hue and Kennedy, 2014). In this context, my analysis highlights curricular-level ambivalence, as sparse, sporadic, and negative attention is given to religion in Liberal Studies textbooks.

\section{Religion in the curriculum and Liberal Studies}

Nearly half of all primary and secondary schools in Hong Kong — private and government— are religiously affiliated (primarily Christian). However, religion has never had a substantive role in the formal curriculum of government schools, where the majority of students are educated today. As Lee (2001, 214) notes, local educational leaders rank religious education as relatively unimportant within formal education, while religious organizations have shifted from “an evangelical approach to a professional approach in running schools” over the last few decades. In government schools, religious education can be taught as an elective (and many schools also teach Confucianism in nonreligious curriculum). However, as the 
proportion of people in Hong Kong who identify as religious is comparatively low, at 38\% (Gilani, Shahid, and Zuettel 2012), and as private Christian schools tend to teach of Christianity rather than comparative religious studies, overall few students today are studying diverse religions substantively.

This lack of formal religious education emphasis in Hong Kong is reflected in the guidelines developed by the Education Bureau for teaching about religion and related topics in schools. The curriculum guide provided for teaching comparative religious education in secondary school (grades 7-9) dates back to 1999. The document has significant inaccuracies. For instance, it describes Jews as Israelites and lists them as Christian believers (CDC 1999, 24). It discusses Islam apparently interchangeably with “Islamism” (CDC 1999, 33). As “Islamism” usually refers to a political ideology related to Islam rather than the religion generically, it is problematic for the text to claim for instance that, "Islamism is a world-wide religion...” (CDC 1999, 33). It seems unlikely that any Muslim individuals or groups assisted in developing the guide.

A more recent (2007) guide to “Ethics and Religious Studies” for senior secondary education (grades 10-12) is also available as an elective. Recognizing the breadth of religious experience is mentioned as a key aim in objectives such as enabling students to "acquire knowledge of...major religions in Hong Kong,” and “develop a positive attitude towards people and respect for their beliefs” (CDC 2007, 2). However, there is little elaboration on how to teach toward these ends in the (over 100-page) guide. The most relevant suggestion is that people view birth control, aging, and suffering, “from different cultural, political, and religious perspectives” (CDC 2007, 9). This is a far cry from learning about religions per se, such as by examining different faith traditions systematically. Most of the "Ethics and 
Religious Studies” curriculum is oriented toward ethics. The guide recommends that 100 hours be spent on ethics and social issues, while 20-36 hours are given to studying either Buddhism or Christianity (it suggests that in the future Confucianism, Islam, and Taoism will also be available choices); a final 70 hours are to be spent in locally-planned service or experiential learning (CDC 2007, 42). Today's "Personal, Social and Humanities Education” curriculum guide (for lower grade levels) similarly discusses that children should learn about religious diversity in Hong Kong education (“to respect...different religious backgrounds,” compare and contrast religions, etc.), without making substantive recommendations on how to reach this end (2002).

Introduced in 2009, Senior Secondary Liberal Studies (SSLS) offers the most ambitious, systematic curriculum with regard to students’ multicultural engagement with diversity, including religious diversity, within Hong Kong government school curriculum. Among other aims, its multicultural aims include:

- ...enhance students' understanding of themselves, their society, their nation, the human world...

- ...develop multiple perspectives on perennial and contemporary issues in different contexts (e.g. cultural, social, economic, political...)...

- ...appreciate and respect diversity in cultures and views in a pluralistic society and handle conflicting values...

- ...demonstrate respect for evidence, open-mindedness and tolerance towards the views and values held by other people...

- ...demonstrate an appreciation for the values of their own and other cultures ... (CDC 2007, 5-6). 
However, specific references to religion are scarce in the 216-page curriculum guide. Typically, religion is listed among myriad factors influencing people’s views. The first reference dealing with religion states, for instance, with regard to government and "different interest groups,” that teachers explore,

the demands from people, organizations and interests groups with different characteristics, backgrounds, ideals and endowments, e.g. political groups, nongovernmental organizations (NGOs), the disadvantaged, professional bodies, industry and business, the middle class, people of different gender, ethnicity and religion. (CDC 2007, 30).

Religion appears as an afterthought within such a list of people and groups with "demands.” Religion is also mentioned in relation to learning about China, and in connection to the challenges posed by globalization. These references are also in lists: e.g., "Does the spread of globalization promote international understanding or cause greater conflict among ethnic groups, religions, cultures and political entities?” (CDC 2007, 41).

Further references discuss possible areas for students to conduct self-directed projects. In discussing religion in such projects, the text states that, "in Hong Kong, religious groups play a very active part in society. In today's world, the role and influence of religion in society differs greatly across and within cultures” (CDC 2007, 148). Particular religions and discussion of roles they can or do play are absent, however. This section also features a list of questions students may explore; the first related to religion is: "Is believing in religion a sign of weakness?” 
The Education Bureau recommends that Liberal Studies teachers not rely upon textbooks, but instead utilize a variety of resources from media, research, etc., which employ and engage multiple perspectives (CDC 2007, 138). In relation, it collects news media and other resources in an online education platform, “HKEdCity,” which educators can access (of course, representation of religious minorities in media can also be problematic; see O'Connor, 2012, 137). However, as a new and interdisciplinary, nontraditional subject, many have found Liberal Studies difficult to teach. While the first cohorts of systematically trained Liberal Studies educators are now emerging from university programs, current Liberal Studies teachers report feeling unprepared (Wong, Chan, and Ho 2012). As a result they rely heavily on textbooks, as teachers are often found to do early in a subject's history, and/or among new or inexperienced teachers (Kaviani 2007). In such cases, the resources provide much of the content of the course, guiding and educating teachers, as well as students. In a 2012 survey, $90 \%$ of SSLS teachers claimed their main source of teaching materials was textbooks, while there are concerns that without government oversight the texts are inadequate to the task (Chong 2012). Students are using largely unexamined resources to learn the new subject.

As Liberal Studies aims to create constructive awareness of local and global contexts, its curricular resources should be examined before use to ensure they reflect accurate and useful viewpoints. Otherwise, it may be difficult for Liberal Studies education to meet its goals of helping students understand, appreciate, and respect social and cultural differences within and across societies. Though textbooks may not be and need not be used in isolation in Liberal Studies, against this backdrop of lack of oversight and overuse, critically examining them is essential. The next section evaluates representations of religious diversity, with an eye to minority religious communities, in the four most popular Liberal Studies text sets (collections 
of textbooks) used today: books for the modules of "Hong Kong Today” and "Globalization” (where most references appear) by Aristo Educational Press, Hong Kong Education Publishing Company (HKEPC), Ling Kee Book Store, and Pearson Education Asia Limited.

I used discourse analysis techniques of text coding and parallel analysis (Bello and Shaver 2011; Fraekel and Wallen 2008 ) to examine how typical, common representations of religions and/or religious people and groups are framed in the texts and relate to the aim of enhancing student understanding and appreciation for diversity in society. As HKEPC and Pearson textbook sets are published in English and Chinese, I conducted an initial analysis of the English version of these texts while a research assistant analyzed the same texts as published in Chinese. The research assistant translated the Chinese-version texts into English before we compared our coding results, to ensure reliability of analysis and reliability of

translation. The other textbooks (by Aristo and Ling Kee) are only published in Chinese. For these, the research assistant independently identified and translated relevant excerpts from the texts for my analysis. Quotations from Chinese-language texts have been provided as translated to English. As the next section shows, there is a focus on negative perspectives on Islam in particular throughout textbooks, with less discussion of Islam (or other religions) that can enhance student appreciation or respect.

\section{Religion in Hong Kong and the apparent threat of Islam}

As in the curriculum guidelines, within Liberal Studies textbooks the most common references to religion are to a generic concept of religion, and as an identity characteristic, within a list of categories of social difference (nationality, ethnicity, race, etc.). Such references do not explore religion, but acknowledge religious diversity in a minimal way. 
They express the existence of religion neutrally, confirming the right to religious practice in Hong Kong and elsewhere.

Many such references are found in discussions of human rights in "Hong Kong Today,” by HKEPC. For instance:

[H]uman rights refer to the rights inherent of all human beings regardless of nationality, place of residence, sex, national or ethnic origin, colour, religion, language or any other status (Hui 2009, Book 1, 58).

Everyone has the same rights as a human being regardless of his/her race, sex, colour, religion, occupation and status (Hui 2009, Book 2, 43).

[R]ights and interests should be respected and one should have the chance to live with dignity, regardless of race, colour, religion, sex, and class. (Hui 2009, Book 2, 31).

In a general way, textbooks emphasize the diverse, multicultural atmosphere and culture of Hong Kong. In this context religion is occasionally mentioned. One typical reference of this kind notes that "Cultural diversity is a cultural characteristic of Hong Kong. The unique fusion of the East and the West, and the new and the old is manifested in aspects, such as food, architecture, language and religion” (Hui 2009, Book 1, 75). However, the religious make-up of Hong Kong is never discussed. Aristo’s “Hong Kong Today” (Ng, Wong and Wong 2010, 245) comes closest. 
Taking religion for example, different religions coexist in Hong Kong, including Catholicism, Christianity, Buddhism, Islam, and Sikhism...Although Hong Kong residents have different religious beliefs, religions respect each other. Religious conflicts never happen...Hong Kong residents respect different cultures, and give communities the right to be heard, enabling Hong Kong to be a multicultural society and maintain stability. (Translation from Chinese)

Apart from such general references, individual religions and religious believers are nearly invisible in the textbooks. There is little description of specific traditions, practices, and believers. Hindus are nearly invisible in the texts, mentioned less than once on average by textbook publishers; one Sikh temple (a photograph) is observed across all texts. There are a handful of references to Christianity and Buddhism within each text set, but a student without past experience with these traditions would still be hard-pressed to understand who and what are involved with them.

The most common way the texts illuminate religious experience in Hong Kong is through pictures of churches, mosques, and temples. Such images of local religiosity are often captioned to emphasize the blend of cultures of East and West: "Traditional Chinese religions and foreign religions coexist in Hong Kong. The photos show the Wong Tai Sin Temple and a Catholic Church” (Hui 2009, Book 1, 83); “There are quite a lot of buildings in Hong Kong which combine Chinese and Western architectural and cultural styles. The photo shows St Mary’s Church” (Hui 2009, Book 2, 156). An Aristo text includes images of a Catholic Church and Wong Tai Sin Temple, side by side (Ng, Wong and Wong 2010, 245). Another image features five girls in hijab, with the caption, "we should respect people with different 
cultures and lifestyles” (Hui 2009, Book 2, 149). Religion in Hong Kong is seen, but hardly understood through this imagery (See Ho’s contribution to this volume).

There is one exception to the discussion thus far-one religion the texts discuss more substantively and with richer detail: Islam. However, in this case, negative generalizations prevail despite the diversity of this community within and outside Hong Kong. As mentioned previously, there are some neutral references to the religion and its followers-mostly images of Muslims in Hong Kong. There is also a passage in one text discussing the life of a Muslim in Hong Kong in some detail: Karim, from Indonesia. The text also mentions practices related to Islam.

Apart from working and preaching in the mosque on Oi Kwan Road, Wan Chai, he also hosts religious radio programmes which are broadcast in the Indonesian language. The audience consists of mainly domestic helpers from Indonesia. He also attends exchange meetings with Christian organizations at least twice a month.

Although the Hong Kong lifestyle affects obedience to Islamic dogmas (such as believers have to pray 5 times a day, women need to use headcovers all the time, they are forbidden to cook pork, etc.), their freedom of religion is not deprived. Karim says that the Hong Kong government does not intervene with the freedom of religion. He can preach outdoors and sometimes even the police will actively help maintain order. (Hui 2009, Book 2, 152).

This is an interesting passage for what it reveals and obscures, as one of the more substantial discussions of Islam, or any religion, in the textbooks. This excerpt does not have as its aim to educate students about Islam, specifically, as such a focus would include, among other 
things, an examination of the pillars of Islam (i.e., testimony of faith, prayer, alms-giving, fasting, and pilgrimage). Instead, it expresses that Hong Kong life influences religious norms. However, there are some problematic features. First, hijab is neither universally practiced among Muslims, nor do Muslim women "need to use head covers all the time.” This is an over-simplification. Second, the passage raises more questions than answers-how does Hong Kong life impact practices? Why do police "help maintain order”? Is praying disorderly, or does it invite social disorder? In general, this passage gives a mixed impression of Islam: Karim is involved in service, exchange across religious communities, and says nice things about living in Hong Kong. On the other hand, cultural contrast, challenges, and the need for police are alluded to, suggesting that Islam is inharmonious within Hong Kong society.

This latter point is also hinted at in some generic references to religion in the texts which suggest that religious believers face problems in Hong Kong. For instance, one text notes that ethnic minorities "may face disputes and conflicts due to their different race, appearance, skin colour, language, living habits and religious beliefs as compared to local Chinese, [which] makes it more difficult for them to establish their identity as Hong Kong people” (Hui 2009, Book 2, 102). Later, the same text suggests that students can learn about ethnic minorities by reading Colors of Hong Kong, to "understand our neighbours free from the influence of skin colour, race and religion” (Hui 2009, Book 2, 153). Subtly religion is also connected to ethnic minority identity in these passages, while no texts portray diverse religious experiences and practices of mainstream, ethnic-Chinese Hong Kongers.

Negatively connoted representations which may enable prejudicial attitudes in the place of understanding and appreciation prevail in the vast majority of further, substantial references 
to Islam and/or Muslims. Though not discussing Muslims based in Hong Kong, numerous discussions across textbooks emphasize Islam as clashing with modernity and/or Western civilization, in a more severe way than in the case of Karim in Hong Kong. In a small subsection of these further references, Christianity is also mentioned as a Western tradition, but it is not framed as a hostile force in comparison with Islam. As Hong Kong is continually described in the textbooks as an "East-meets-West" society and culture, references to Islam clashing with Western civilization may also be read to imply Islam as a potentially negative force within Hong Kong. Discussions of Islam and Muslim groups and societies as factors or sources of global cultural clash refer to terrorism and Samuel Huntington's “clash of civilizations” thesis (1993), and to Muslim women’s rights and hijab. Reflecting approximately one-fourth of coverage related in any way to religion in the textbooks, these references provide a window into the sorts of cultural attitudes students may develop toward religion, and particularly Islam, through Liberal Studies.

Pearson and HKEPC texts focus on the "clash of civilizations" view of Islam substantially, and offer support for the thesis. In the Pearson second booklet for “Globalization” (Ngai 2010), Huntington's views are given with some minimal challenges offered (emphasis has been added by the author to highlight explanations which can be read by students as objective, “factual” statements).

The Clash of Civilizations, proposed by Samuel P. Huntington in 1993, suggests that...the increase in East-West communication may highlight differences between the two civilisations, and lead to another kind of conflict—-the clash of civilisations. The most serious have occurred between Western and Islamic civilizations. (90) 
...According to Samuel P. Huntington's theory, religion is the most important element for distinguishing civilisations. Two groups of people within the same nation can have conflicts if they have different religions. He indicated that civilisation is not equivalent to a nation state, and that the biggest difference between people is in their values, social system and religion...Therefore, values, moral standards, social systems, and religion are the main reasons for human conflicts and disagreements. (93)

There has been a revival of Islamic fundamentalism is Islamic countries in recent years. Fundamentalists emphasise that when their religion is under threat, they must embrace classic Islamic rules. As there is a concept of jihad (holy war) in Islamic teaching, some extremists may use radical and violent means in order to counter Western Christian civilisation. (96).

These pages are accompanied by grave images. One photograph shows the September 11 , 2001 (9/11), attacks on the World Trade Center’s twin towers in New York City, with the caption: "Some scholars believe that the 9/11 incident was caused by conflicts between Western civilisation and Islamic civilisation as well as various social and political factors.” A second picture shows an unknown, angry-looking man, with the caption, “An Islamic extremist intimidates to launch a terrorist attack to revenge the invasion of Western culture.” An image of Osama bin Laden in camouflage with a voice bubble rejecting "the invasion of Western culture,” is featured, as well as a picture of Pakistani men burning an American flag, "to vent their anger [after] the US air force mistakenly bombed a tribal area."

Problematic in the extracts above is the definition of jihad as "holy war," which is not the exclusive definition of jihad, as it normally (traditionally) bears a broader meaning of 
struggle and effort. The discussions have been simplified in ways that support the clash view: clashes of civilizations "have occurred”; values and religions "are the main reasons for human conflicts.” Dramatic images negatively portray Islam here, connecting 9/11 to Islam, and suggesting that Muslim men are normally violently reactive and might commonly plot terrorist attacks on Western societies.

The same book (Ngai 2010) also goes on to discuss some criticisms of the clash thesis.

The Clash of Civilizations is widely accepted as it somewhat explains the long-term hostility between Western and Islamic countries. However, some of its viewpoints have been criticised by scholars.

Clashes are avoidable: Despite differences, people of various civilisations have many opportunities to communicate and understand each other...As long as people respect and understand each other, they can not only prevent conflicts, but also achieve harmony...The 9/11 incident vindicated some viewpoints of the Clash...but even Huntington himself admitted that his theory did not reflect the whole truth. A few Islamic countries (e.g., Turkey) do not have conflicts with Western countries; they have assimilated...

The views of people in the same civilisation camp may differ: ...For example, during the Iraq war, European countries and the US, which belong to the same type of civilisation, split into two sides according to... whether troops should be sent... Criticism of the "China Threat" Theory: ...Huntington indicates that China... has the ability to ally with Confucian or even Islamic countries to counter the common enemy_Western civilization. However...many mainland Chinese scholars...think 
that Confucianism, which promotes peace, will not become a threat... (96-97; emphasis in original).

This discussion features the only picture of (identifiable) Muslims not engaged in worship (or at mosque), terrorism, or wearing hijab across texts, showing “a Muslim couple in modern Turkey having a Western-style wedding.” However, the structure of the text, which presents the clash view, and then some limited criticism of it-which is apparently also led by Huntington—casts Huntington as the prominent figure and thinker; his critics, such as Edward Said (1997), are absent. Additionally, the discussion of criticisms frames the clash view as "widely accepted” and "somewhat” validated. Despite recognition that people may differ within a civilization or relate to each other across civilizations, the civilizational discourse is treated as legitimate, precluding a critique of Huntington's level of cultural analysis (Said 1997).

The HKEPC texts also discuss “clash of civilizations” favorably. One extract suggests (again) that "invasion of culture" was a chief reason for the $9 / 11$ attacks.

[U]sing the culture of the mainstream group to unify or assimilate other cultures, not only discourages different groups to build multiple identities but also causes them to feel lost and confused.... some scholars pointed out that the 911 terrorist attacks on the United States of America resulted from conflicts between Christian views in the West and Islamic views in the Middle East. Islamic extremists made the attack to express their discontent with the invasion of Western culture. Although the background of the 911 incident is so complicated that its origin cannot be generalized by cultural conflict, 
it certainly inspired people's thoughts on cultural conflicts and social stability. (Hui 2009, Book 2, 146)

Again, an image of New York on 9/11 is featured. This passage is quite ambiguous: "Some scholars" is vague, while "pointed out" seems to conflict with the final part of this excerpt, wherein it is acknowledged that 9/11 was "so complicated." That those who took responsibility for the attacks attributed their actions to cultural invasion is inappropriately simplistic; such a sense of invasion was expressed as military and political.

In another discussion, a “Globalization” HKPEC text legitimates the clash view by comparing Islam to the West as civilizations in broad strokes.

The social order of Islam is opposed to some prominent western values. For example, human rights, democracy and gender equality are incompatible with the Muslim religious doctrine. In Islam, it is not the individual and his free will that counts, but faith and religious struggle. (Wong 2010, 51)

This text is accompanied by an image of two women in hijab, with the caption, "In countries where people believe in Islam, female status is relatively low, which is opposed to the Western values of gender equality.” This framing of Islam as dichotomous to Western civilization follows the clash thesis by viewing the cultures and their values as separate, while discounting other views, such as that often Westerners and Muslims live side-by-side, and that women's rights and status are hardly rejected across diverse Muslim societies (while, on the other hand, gender equality has hardly been fulfilled across western societies and Christian communities). To state that Muslim dogma disallows democracy or human rights is 
also debatable and controversial. A lack of specificity here and attention to complexity within Islam strengthens an anti-Muslim view within the texts.

In the next page, Huntington is introduced.

In 1993, Samuel Huntington published his work...which pointed out that world politics is entering a new era. Conflicts will not be the same as those in the 20th century...

Huntington especially shows concern for 'wars' between Western and Islamic civilizations. He argues that the Islamic civilizations are greatly influenced by the Western ideologies and values such as democracy, human rights and the rule of law. The great differences in values of civilizations can even result in conflicts and competition. The September 11 attacks were regarded as an example of Huntington's analysis. (Wong 2010, 52; emphases added).

This text is also accompanied by a picture of the explosion of the World Trade Towers in New York, with the caption, “The September 11 attacks in 2001 were regarded as a confirmation of Huntington's views.”

A sort of debate is also invited here, this time with reference to Said.

[Edward Said] criticized that the objective of the clash of civilizations raised by Huntington is to restate the ideology of the Cold War in a sarcastic way. He argued that Huntington's view would cause more conflict and reduce the harmonious interaction between civilizations. Edward Said claimed that a civilization is not 
always homogeneous or closed. For a long time, there has been frequent cultural interactions among civilizations, which override the view raised by Huntington that all civilizations are in closed systems. (Wong 2010, 53).

This discussion is accompanied by an image of Orientalism, and a cartoon:

Samuel Huntington: Cultural conflicts and the clash of civilizations are the main features of the current struggles all over the world, especially the 'wars' between Western and Islamic civilizations.

Edward Said: ‘Orientalism’ shows the false assumptions underlying Western attitudes towards the Middle East. Your theory of the 'clash of civilizations' will only generate more conflicts and lead to less dialogue among civilizations.

An attempt at offering a balanced perspective is made here. However, more substance is offered for Huntington’s view, with the connection drawn to 9/11 (vividly illustrated in the textbooks), and with the earlier discussion of how Western and Islamic values are simply different.

Another reference to jihad is made in the same text, in discussing the Arab-Israeli conflict. The text states that in 1948, "the Arabian countries denied [the proclaimed new state of Israel] and jointly declared 'Jihad' (Holy War) on Israel. The US has been criticized for favouring Israel...” (Wong 2010, 134). However, no such joint declaration of jihad was made, although the Arab League did reject the United Nations partition plan and establishment of Israel. 
A final theme relates to Muslim women's rights and dress. As mentioned previously, many women in hijab are portrayed in the texts, and hijab is related to gender oppression and the religious tradition. HKEPC texts discuss that women "need to wear [hijab] all the time" (emphasis added). Beyond these excerpts, texts also emphasize that Muslims "cannot wear clothes that are too thin or too tight.... a woman must have her entire body covered” (Wong 2010, 149). No diversity within beliefs and practices is noted here, despite the fact that Muslim women within and across countries practice hijab in diverse ways. The passage starts with the statement that, "under the special cultural backgrounds of some societies, people are generally resistant to foreign cultures....Islamic teachings are different from other cultures in that it is hard for its followers to accept other cultures." Such statements suggest homogeneity rather than heterogeneity of religious practices, and present a dichotomy between Muslims and non-Muslims worldwide, presenting a Muslim world that is static and archaic, when the movement of culture, values, practices, and norms within and across Muslim societies is not uncommon.

Muslim women's dress is discussed sympathetically in some sections of the Pearson and HKEPC guides. In one cartoon, Hong Kong students discuss globalization, homogeneity, and the conservation of cultural practices and hijab:

Jack: Muslim women still wear traditional Islamic clothing. May: Under globalization, hasn’t western fashion influenced Islamic countries? Peter: It’s all about preserving one’s culture. A lot of people would never make concessions about certain values. Imposing one’s own values on others may end up causing conflicts! 
Claire: Don’t exaggerate! I believe globalization promotes cultural exchange and homogenization, and fosters friendship among countries. (Ngai 2010, 84)

Although there is no strong narrative voice given here, and the overall meaning of views conveyed is mixed, hijab is at least mentioned here, not as an exotic, conservative difference and/or symbol of gender oppression in Muslim societies, but also as a possibly worthwhile practice to preserve in the face of globalization.

A discussion of the ban of hijab in French public institutions is also discussed in the HKEPC text in a more complex, mixed way.

Islamic full veil is regarded as a threat to the public safety, as those who have full veil cannot be identified easily. It also damages women’s rights. The above ban is widely supported by the French public. However, Islamic women claimed that this would damage their dignity, rights and freedom. They also expressed that the law will probably force them to stay at home. So, it is strongly opposed by the Islamic citizens. (Wong 2010, 62).

Yet the choice to simplify again paints cultural difference and politics in two broad strokes. Not all French people support the ban, while not all Muslims in France reject it (Jackson 2005). Taken as a whole, with but one slight reference to cultural heterogeneity in Turkey, the Muslim world is portrayed boldly as monolithic in culture, values, politics, and origin/ethnicity (as all Muslims in the texts are from Arab countries and/or Western Asia); and as sexist, patriarchal, and oppressive. The discussion of Karim is the only examination of Islam or Muslims which might encourage an appreciative interest or positive recognition 
among students; the rest are likely to cause students to feel suspicious or possibly even offended by the religion and its followers.

\section{Discussion}

It is challenging to interpret the text discussions described in the last section as fulfilling the curricular aim of Liberal Studies, of enhancing student understanding of "the human world" and multiple perspectives across cultural contexts, and developing appreciation and respect for cultural diversity and plural values and views (CDC 2007, 5-6). After all, the world is full of religious believers, within Hong Kong and outside it. Yet from the text extracts dealing with religion(s) nominally or substantially, students are unlikely to gain any understanding of religious beliefs, values, or practices that they have not previously encountered. Though diversity and cultural meetings are continually discussed, in more and less critical, positive, and negative ways, the substance of diversity—-the who, what, where, and how—are missing. There are Christian buildings in the textbooks, but few Christians, apart from in discussions of large-scale Western civilization and/or culture. Likewise, Buddhist temples are featured in images, but a non-Buddhist would not learn anything about Buddhism from these textbooks. Judaism, Hinduism, and Sikhism are each once mentioned (not discussed) across the four publishers' text sets.

When it comes to discussing Islam and Muslims in a way that can develop students' understanding of the breadth and depth of experience, these textbooks also fail. Though some diversity within Islam can be seen across the various publishers' textbooks as a whole, there are only a few mixed, balanced, neutral, or positive discussions or illustrations of Islam or Muslims, in Hong Kong or worldwide, within each text set (thus, there is relative diversity of 
representations in this analysis, but not in normal school experience, where students typically only access one publisher’s books). Within each text set, several negative discussions and depictions of the religion can be found, which emphasize terrorism and gender oppression as if they are universal aspects characterizing Muslims worldwide. Students are unlikely to develop a sympathetic understanding of Muslims from such discussions, but instead may learn to view them prejudicially, as sexist, patriarchal, backwards, and hostile to cultural diversity and social integration. This neither aids the student in learning about difference in this case, nor does it aid Muslims in Hong Kong society or worldwide, who face prejudice and discrimination when their religion is misunderstood and reduced to terrorism, jihad, and hijab. Overall, the Liberal Studies textbook coverage of religion and religious diversity is at odds with framings that can effectively enhance understanding and respect for difference.

Nord (1995; 2010, 220) argues that in social sciences and particularly history, where religion should be a major component of curriculum, religion is often avoided, due to controversy and anxiety over addressing taboos in the classroom, and given a "preoccupation of the texts with political, social, and military history." He argues that part of the reason for this is the use of an integrative approach to religion, discussing religion as part and parcel of the economic, social, and cultural world. Such an approach has merit; yet it often ends up obscuring religion's role in practical matters, as the curriculum easily focuses in such cases on political and economic events, giving minimal attention to religion. Deng similarly points out the role of Liberal Studies to re-politicize Hong Kong curriculum from the colonial era, while offering an integrative approach to political, social, and cultural aspects of local life (2007). Inevitably in such a schema, religion becomes a secondary or tertiary concern. Such trends toward integration of the social sciences in educational curricula which wind up precluding rigorous examinations of religion lead Nord to ask, "if there can be occasional chapters on 
railroads or popular culture why can’t there be an occasional chapter on religion?”acknowledging that while everything religious may be unfortunately "shunted into such a chapter," this may nonetheless be better than an approach wherein students only glean the slightest information about religion as an important part of the social world (2010, 221).

A “comparative world religions" schema can be helpful in such cases, as it better illustrates to students how religion helps people find meaning across societies worldwide. It can better enable appreciation for diversity, respect, and tolerance, as comparative frameworks aim to be objective, and give accurate, equal representation to different religious and world views. It can give students more in-depth understanding across religions, as it presumes that one should not give more (or more positive) information about one religion than another, when attempting to offer a window to students about religion in their society or worldwide. Such a comparative lens aims to avoid bias or stereotypical representation, by giving accounts that are fair according to the terms of different traditions and communities, and their desire for positive tolerance and recognition, rather than framing them according to other purposes (Hoosain and Salili 2006; Wilson 2006). Such an approach could be a step in the right direction for Hong Kong, if educators truly want students to learn something of the rich human diversity of the society and the world today.

\section{Conclusion}

According to Liberal Studies textbooks, Hong Kong society is proudly free and nondiscriminatory regarding speech, belief, and religious expression; it is a blended hybrid culture of East and West, Chinese and international, which meets the challenges of globalization with tolerance and a liberal, rights-based perspective toward difference. Such a self-image is aligned with the curriculum's explicit multicultural aims, to understand and 
appreciate social diversity and plural values and cultures. This optimistic outlook about diversity and globalization paves the way for more inclusive notions of what Hong Kong society is, who Hong Kongers are, and how to develop the society as a model of multiculturalism, tolerance, and dynamism. Additionally, it casts students as future decision makers, who should protect minorities, ensure equality and eliminate discrimination, and uphold related multicultural attitudes and values.

However, despite the importance of religion to diverse people's beliefs, values, and practices today, the ins and outs of religious diversity in Hong Kong and worldwide is barely addressed in the Liberal Studies textbooks. There is no explanation in any of the most popular Liberal Studies textbooks of the main beliefs and practices of any religious community—or of the religious make-up of Hong Kong, or the demographics of its religious believers (for instance, that ethnic-Chinese people may also participate in minority [or mainstream] religions in society). Where coverage is more substantive, in discussing Islam, discourse is often heavily negatively biased. Muslims are cast as sexist, patriarchal, and backwards. Liberal Muslims, feminist Muslims, Chinese Muslims, and Muslim women who do not wear hijab do not exist in the textbooks. Students can hardly learn how to understand and appreciate religious difference in their society or worldwide from such textbooks. Instead, they may enable bias and prejudice, as students are likely to imagine that all Muslims are the same from such overgeneralized, oversimplified discussions.

It is unlikely textbook publishers aimed to perform poorly with regard to the multicultural aims of Liberal Studies, despite the incomplete, partial views of religiosity they provide. Historically, Hong Kong educators have not focused on systematic religious education in public schools. Additionally, as an integrated approach to social studies curriculum, Liberal 
Studies has a significant challenge to depict economic, political, cultural, and other domains adequately, symbolizing a re-politicization of curriculum from the colonial period. As politics and economics are often held as two of the most important lenses for understanding the modern, globalizing social world, religion can easily become a secondary or tertiary concern: one factor within a list of competing issues or categories of social difference which educators must address in the course of an ambitious, interdisciplinary, multifaceted social sciences and current events curriculum. Finally, as educators are encouraged to utilize a variety of resources apart from textbooks in teaching Liberal Studies, textbook publishers have hardly been given a mandate to adequately fulfill all curricular aims.

Nonetheless, the lack of balanced, clear explanations about religious diversity in the textbooks is detrimental to the multicultural aims of the curriculum, given Liberal Studies educators’ reliance on textbooks in teaching the course. As reflections of Hong Kong educators' common (latent) knowledge, the lack of sensitivity and specificity with regard to religious expressions and experiences is also disturbing. To cast nearly one-quarter of the world's religious believers (Muslims) as homogeneous betrays a lack of multicultural understanding, appreciation, and commitment. To continually express pride in equality, diversity, and nondiscrimination, without systematically describing minority experiences, is to encourage a shallow engagement with diversity, in place of constructive dialogue and reasoned analysis of important issues of social difference in good faith. Teachers may use other resources to teach Liberal Studies beyond the texts-but against the wider backdrop of challenges in multicultural education in Hong Kong (Hue and Kennedy 2014; Law and Lee 2012), there is little reason to believe other resources used are necessarily more balanced, or that teachers’ own pedagogical messages are otherwise more multicultural than prejudicial (Jackson, 2014). 
In this context, one cannot expect Liberal Studies teachers to be experts where textbook publishers are not. For Liberal Studies to ensure its multicultural aims are met, textbooks should be written with the advice of multicultural curricular experts and/or through consultation with minority groups (including religious minority groups) in society. Additionally, more should be done in teacher education and in-service training to elaborate methods, practices, and resources for teaching students about diversity and religion. Lacking these provisions, it is unlikely students will learn to understand religious difference, minority expressions of religion, or how religion can impact social life in a productive way, as required to meet Hong Kong’s educational commitment to sustaining an open, liberal democratic society.

\section{Acknowledgements}

The author wishes to thank Shao Yanju for research, translation, and transcription assistance. This work was supported by the University of Hong Kong University Research Committee Seed Funding for Basic Research Scheme [201211159020]; the Research Grants Council of the University Grants Committee of Hong Kong Early Career Scheme [758713].

\section{Note on Contributor}

Liz Jackson is Assistant Professor of Curriculum and Policy Studies in the Faculty of Education at the University of Hong Kong. She has published in the areas of religious education, philosophy of education, and moral education. Her new text is Muslims and Islam in U.S. Education: Reconsidering Multiculturalism (Routledge, 2014). lizjackson@hku.hk

\section{References}


Bello, Manuel, and Annis N. Shaver. 2011. "The Representation of Christopher Columbus in High School History Textbooks: A Content Analysis.” In The Textbook as Discourse: Sociocultural Dimensions of American Schoolbook, edited by Eugene F. Provenzo, Annis N. Shaver, and Manuel Bello. New York: Routledge.

Chong, Dennis. 2012. "Liberal Studies Failing to Meet Goals Set for It,” South China Morning Post, 6 July.

Curriculum Development Council. 1999. Syllabuses for Secondary Schools: Religious Education. Hong Kong: The Education Department.

Curriculum Development Council. 2002. Personal, Social and Humanities Education: Key Learning Area Curriculum Guide. Hong Kong: The Education Department.

Curriculum Development Council and Hong Kong Examinations and Assessment Authority. 2007. Ethics and Religious Studies: Curriculum and Assessment Guide. Hong Kong: Education and Manpower Bureau.

De Leon Mendiola, Annalisa. 2007. Traditionalists versus Multiculturalists: Discourses from the 2003 U.S. History Textbook Adoption in Texas. EdD diss., University of Texas at San Antonio. 
Deng, Zongyi. 2007. “The Formation of a School Subject and the Nature of Curriculum Content: An Analysis of Liberal Studies in Hong Kong.” Journal of Curriculum Studies 41 (5): 585-604.

Foster, Stuart J., and Keith A. Crawford. 2006. What Shall We Tell the Children? International Perspectives on School History Textbooks. Greenwich: Information Age Publishing.

Fraekel, Jack R., and Norman E. Wallen. 2008. How to Design and Evaluate Research in Education. New York: McGraw-Hill.

Gilani, Ijaz Shafi, Shahid, Rushna, and Irene Zuettel. 2012. Global Index of Religiosity and Atheism. Zurich, Gallup International.

Hoosain, Rumjahn, and Farideh Salili. 2006. “Introduction: Dimensions of Religion in Multicultural Education.” In Religion in Multicultural Education, edited by Farideh Salili and Rumjahn Hoosain, 1-8. Greenwich: Information Age Publishing.

Hue, Ming-tak, and Kerry John Kennedy. 2014. “Creating Culturally Response Environments: Ethnic Minority Teachers’ Constructs of Cultural Diversity in Hong Kong Secondary School.” Asia Pacific Journal of Education, 34 (3): 273-287.

Hui, Tai Mei Har. 2009. Liberal Studies: Hong Kong Today, Book 1. Hong Kong: Hong Kong Education Publishing Company. 
Hui, Tai Mei Har. 2009. Liberal Studies: Hong Kong Today, Book 2. Hong Kong: Hong Kong Education Publishing Company.

Huntington, Samuel P. 1993. “The Clash of Civilizations?” Foreign Affairs, Summer.

Jackson, Liz. 2005. “Choice Versus Equal Opportunity: What Toleration Requires in the Case of the Hijab in French Schools.” In Philosophy of Education 2005, edited by Kenneth R. Howe, 272-274. Urbana, Ill.: Philosophy of Education Society.

Jackson, Liz. 2011. “Islam and Muslims in U.S. Public Schools Since September 11, 2001.” Religious Education 106 (2): 162-180.

Jackson, Liz. 2014. Muslims and Islam in U.S. Education: Reconsidering Multiculturalism. London: Routledge.

Kaviani, Khodadad. 2007. Teachers' Gatekeeping of the Middle East Curriculum. PhD diss., University of Washington.

Lee, Wing On. 2001. “Hong Kong: The Quality of Self in Citizenship.” In Values Education for Dynamic Societies: Individualism or Collectivism, edited by William K. Cummings, Maria Teresa Tatto, and John Hawkins, 207-225. Hong Kong: Comparative Education Research Centre. 
Law, Kam-Yee, and Kim-Ming Lee. 2012. “The Myth of Multiculturalism in 'Asia’s World City’: Incomprehensive Policies for Ethnic Minorities in Hong Kong.” Journal of Asian Public Policy 5 (1): 117-134.

吳，麗芳，明樂黃和天賜黃。今日香港。雅集:香港，2010。

(Ng, Lai Fong, Ming Lok Wong and Tin Chi Wong. Hong Kong Today. Aristo: Hong Kong, 2010.)

Ngai, Pak Kui. 2010. Liberal Studies: Globalization II. Longman, Hong Kong.

Nord, Warren A. 1995. Religion and American Education: Rethinking a National Dilemma. Chapel Hill: University of North Carolina Press.

Nord, Warren A. 2010. Does God Make a Difference? New York: Oxford University Press.

O’Connor, Paul. 2012. Islam in Hong Kong: Muslims and Everyday Life in China's World City. Hong Kong: Hong Kong University Press.

Peng, Chih-ling, and Shin-rou Huang. (2012). A Study of Gender Ideology in Taiwan Elementary School Textbooks: Perspectives from Textbook Editors and Reviewers. Paper presented at Philosophy of Education Society of Australasia.

Said, Edward W. 1997. Covering Islam: How the Media and the Experts Determine How We See the Rest of the World. New York: Vintage. 
Wilson, H.S. 2006. “The Other/Neighbor in World Religions: An Exploration from a Multicultural Education Perspective.” In Religion in Multicultural Education, edited by Farideh Salili and Rumjahn Hoosain, 9-40. Greenwich: Information Age Publishing.

Wong, Ka-Lok, Chan, Eva, and Loretta Ho. 2012 “Implementation of NSS Liberal Studies Curriculum: A Comprehensive Study.” Paper presented at the Faculty of Education, University of Hong Kong, Hong Kong, July 6.

Wong, Sharon. 2010. Globalization II. Hong Kong: Hong Kong Education Publishing Company. 